investigations | jeremy strong

\title{
The Modern Offal Eaters
}

Regarded, variously, With SUSPicion, revulsion, and delight, offal constitutes a topic of undoubted, if conflicted, interest. Rather than objectively charting the nutritive and gustatory properties of such stuff as kidneys, sweetbreads, pigs' cheeks, and brains, however, I propose to look at how offal is discussed and characterized in today's food media, a network composed of people and publishing and television programs that helps shape both what and how many of us eat. The values of offal are in part dependent on how it is prepared and consumed, a notion that may be elucidated by the ideas of Pierre Bourdieu. In turn, offal's traditional lowly place in the hierarchy of foodstuffs has resulted in its having been labeled a "cuisine of the poor," another idea that warrants closer attention.

Both anthropological cultural studies and a wide range of recent cookbooks and cookery writing relegate offal to the food practices of the poor and hence to a time, in Anglo-American society at least, when poverty was more widespread. Carole Counihan and Penny Van Esterik maintain that "Culturally and economically marginal people often suffer hunger and malnutrition and rarely eat meat, or they only eat despised cuts or innards, some of which may serve as the foundations of entire cultural cuisines, as pigs' feet, chitterlings, and cracklings do in the African-American culture of the southern United States." For Anissa Helou, a specific example of the correspondence between offal and privation may be discerned during British wartime meat rationing: "One of the main reasons why offal went out of fashion in Britain after the second world war was that it had become the only meat readily available during the years of rationing. The association of offal with hard times probably explains why the British turned away from it once meat became more widely available again." ${ }^{2}$

Such understandings fail to recognize and account for the place of offal in contemporary food culture. Indeed, the consumption of offal has become largely the preserve of an affluent culinary cognoscenti whose cooking and eating habits are significantly determined by what they see and read. The very cookbooks and cookery programs on television that repeatedly assert the relation between offal and the thrifty peasantry have as their audience a middle class seeking distinction through what and how they eat. The least prosperous in our society, the reputed consumers of offal, are the least likely actually to eat it. Far from being the inheritors of a domestic wisdom of "making the very best of what they had. Which in many cases was sweet ${ }^{* * *} \mathrm{k}$-all," 3 they are shackled to prepared foods to which the "value" has already been added; and they are estranged - by price, by mode of address, by pride-from the range of media products that repackages their patrimony for sale to others. Offal has been stolen.

\section{Yuck!}

Cookery books that seek to address the topic of offal invariably assume that they must persuade readers of its pleasures in a manner that books concerning, for example, chocolate, do not. Such persuasion finds recourse both in the romance of geography - through the invocation of places and cultures such as France, Italy, or the Arab world where offal eating is the norm - and in the nostalgia of history, through reference to times when it was the norm. Prefatory acknowledgments that offal is now widely regarded among British and North American diners as something to be avoided are commonplace. Hugh Fearnley-Whittingstall, in The River Cottage Meat Book, explains the potential for revulsion thus: "There's no getting away from the fact that we are talking body parts here-organs and glands, no less-and that this is where meat becomes unapologetically anatomical." ${ }^{4}$ In her essay "The Sins of the Flesh," Margaret Visser concurs that it is the inescapable part-ness of certain meat products that renders them more challenging than comparatively nonattributable cuts: "But whereas 'meat' is reasonably imprecise and unconnected in our minds with specific body parts, the same cannot be said for eyes, testicles, ears or offal. The sight of these, especially when raw, is capable of arousing a shudder even in meat-eaters." 


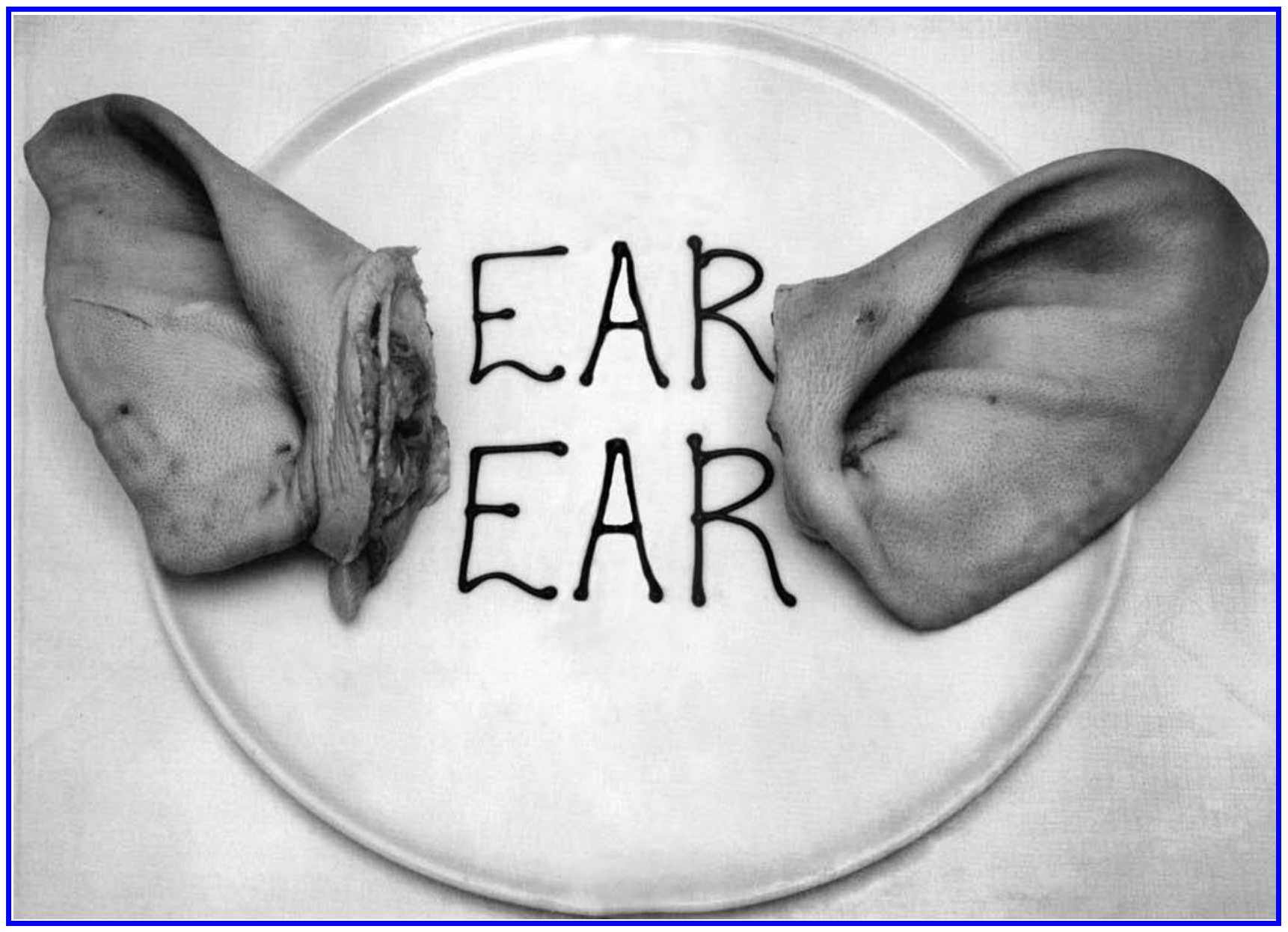

Helou adopts, in The Fifth Quarter: An Offal Cookbook, the stratagem of reminding readers of what she calls "the acceptable face of offal": food items including fish roe, chicken wings, sausages, and pâtés that they may eat "without even realizing they are eating offal." If this is the case, why not, she exhorts, "put aside your prejudices and squeamishness and try some of the more extreme bits." ${ }^{6}$ Yet such appeals coexist with images and descriptions selected precisely for their capacity to provoke the squeamish. Fergus Henderson's Nose to Tail Eating: A Kind of British Cooking opens with a double-page spread of a pair of raw pig's ears on a white plate, the words "EAR EAR" piped between them. ${ }^{7}$ FearnleyWhittingstall includes a sequence of photographs that charts the journey of his cattle from farm gate through slaughter at a local abattoir, and Helou offers inter alia this account of a butcher's shop in Beirut:

Skinned sheep's heads looked amazingly and scarily alive, their bared teeth fixed into a leering grin, the mouth just open enough to let the tongue hang out at the side as if mocking the passers-by. Intestines were pumped full of air and curled surprisingly attractively in buckets, while feet were stacked neatly and cleanly on marble counters. Stomachs were spiked through meat hooks and hung in pouches alongside the heart, lungs and liver. Testicles were left attached to the halved carcasses to indicate the gender. ${ }^{8}$
Such titillation by frankness operates as part of the hard "truth" about animal husbandry, meat production, and food, a communion of knowledge to which readers are admitted and/or assumed to be already in sympathy. This acculturating discourse is posited as existing in contradistinction to a soft majority worldview promulgated by the supermarket experience of easy-to-swallow packaged meat that elides economic reality and anatomical fact. The recurrence of diagrams indicating the location of cuts, joints, and organs in animal carcasses constitutes the most obvious effort to reassert that which is denied by the wiles of industry and the deliberate myopia of shoppers. In Eating England: Why We Eat What We Eat, Hattie Ellis reveals one of the ways in which she employs her grasp of porcine structure:

I'll watch a side of pork being divided into belly and loin on the scooped butcher's block, or see where the chunks come from for a stew. You can play the sequence in your mind of the animal turning into cuts and then rewind it, speeded up, so the cuts leap back to become a whole again. The vegetarian may cringe, but to recognize that meat comes from an animal is to value it more, to give it respect. ${ }^{9}$

Fearnley-Whittingstall echoes these sentiments, affording offal a special place in one's ability to understand an 
animal as a whole: "Offal offers us a chance to pay our respects, in a full and holistic manner, to the animals we've raised for meat." To consume the entire animal rather than reject certain parts as undesirable is also characterized as the practice of an environmentally conscious morality, the hallmark of "cultures more in tune with their environments, and more fully and mutually engaged with their livestock." 10

The significance afforded to food knowledge in this moral scheme, of understanding anatomy and origins, is confirmed by the regard in which mechanically recovered meat (MRM) is held. Fearnley-Whittingstall describes "mechanicallyrecovered pork slurry, blasted off the carcasses of factory-farmed pigs with high-pressure hoses, then hoovered up off the abattoir floor." 11 A range of cookbooks and programs have evinced a similar distaste for the process, its products, andon occasion - its consumers. That MRM represents the use of "any remaining meat" 12 does not appear to afford it an equivalence of virtue to a small-scale farmer's thrift. On the contrary, the practice is consistently described in terms of an industrial-scale deception whereby unpleasant materials are given palatable disguises and sold to a gullible public. It is the consumer's lack of knowledge, as opposed to the insider's wisdom of the offal eater, that makes mRM bad.

In 2005 the question of MRM acquired a new importance in British public life and political debate as a consequence of the television series Jamie's School Dinners, in which the TV chef Jamie Oliver endeavored to effect changes in the meals served in schools. In many scenes children expressed their preference for the re-formed meat products with which they were familiar over the new offerings, which were selected on the basis of affordability, wholesomeness, and the property of honestly expressing their origins and nature. The latter quality was stressed as being especially absent from school food, this absence both reflecting and perpetuating a widespread ignorance among schoolchildren regarding foodstuffs and culinary matters. One product in particular-the Turkey Twizzler-achieved brief notoriety as a paradigm of the "dishonest" food favored by institutional providers for its cheapness, ease of final preparation, and innocuous shape, taste, and texture that belie the realities of its production. A memorable scene featured Oliver convincing primary schoolchildren of the virtues of chicken legs over the chicken nuggets they preferred. His coup de théâtre was to replicate in the classroom the production process of their favorite, using raw chicken parts and a blender. After brandishing the resulting paste, Oliver asked the children if they wanted to eat such stuff and, now that they knew what they were eating, if they still liked chicken nuggets. Later the children were seen enjoying a lunch of chicken leg and salad they had helped to prepare. The episode was represented as constituting a critical phase in Oliver's plans and evolving thesis: recognizing that children would be more willing to change what they eat once they were involved in its preparation and understood what they were eating.

An interesting elision underpinned his success: the question of when "yuck" is the proper response. For Oliver's purposes, the yuck-eliciting deconstruction/reconstruction of the chicken nugget proved a useful trick, provoking both the visceral distaste of his immediate audience as well as helping cement for many viewers the idea of a connection between big business and bad food. Just as the product becomes nasty to the children because of its ingredients, so it becomes nasty to viewers because its consumers did not know what those ingredients were.

If the constituency of eaters changes, however, the question of yucky constituents changes, too. Nose to Tail Eating-endorsed by Oliver as "An essential book for honest cooks"13 - includes, for example, a recipe for haggis that requires a mincer and " 1 sheep's pluck, which should include the heart, lungs, windpipe, liver, and some intestines." 14 Stripped of their other, social significances, the raw facts of haggis and chicken nuggets have much in common: both are composed of elements widely regarded as unappetizing in their original form, and both involve a process whereby small pieces are recombined to create an artificial whole that ameliorates the texture and appearance of those original elements. The quality of honesty that may be attributed to the haggis and Henderson's food generally must therefore reside not so much in the food itself-though bad food seems to be characterized as intrinsically bad-as in the relation between the food and its consumers. When eaten by informed consumers, no substance is, purely of itself, damnable.

What emerges as significant here is a division that is profound but by no means new (though it always finds new means of expression) between differently favored social groups. The series deliberately chose schools, families, and individuals to force a confrontation between their tastes and sensibilities, on the one hand, and Oliver's set of culinary and cultural affiliations, on the other. Heavily promoted before its launch and throughout its run, the series not only offered viewers the pleasure of seeing a popular TV chef engaged in another altruistic venture ${ }^{15}$ but also promised the frisson of an engineered quarrel between blue-collar culture and jeunesse dorée. Oliver was an interesting vehicle, a veritable Trojan horse, in that his affability and "mockney" (mock or pseudo Cockney) persona concealed the extent to which his values were set to clash with those of the recipients of his benign intervention. Most striking was his failure to acknowledge 
social differences, a failure that ensured his bafflement when his food was initially unwelcome. What for Oliver was simply a straightforward proposition with regard to food and wellbeing was discerned by many parents, cafeteria workers, and children as a wider assault on their established tastes and practices, an impugning of how they thought, lived, and worked. Although school food was the particular focus, the programs ranged more widely, encompassing scenes of food at home and health-care professionals decrying the parlous diets and associated ailments endemic in deprived areas. For viewers so disposed, a familiar theme could be extracted alongside the exhortations to politicians, local authorities, and food producers: that the poor, through their actions and choices, are also the authors of their own misfortune-in this case the failure through churlishness, laziness, and ignorance to value good food and to cook and eat properly.

\section{Offal and Distinction}

In Distinction: A Social Critique of the Judgement of Taste, Pierre Bourdieu examined the preferences of middle-class France. Surveying the choices made across a cultural spectrum that included leisure activities, musical tastes, clothing, and food, he considered the significance of educational level and social origin in structuring preferences. Determining that our tastes are learned, rather than the product of inchoate powers of discrimination, his ethnographic study points to the role of tastes in social judgment and in sustaining hierarchies of power. ${ }^{16}$ The present invocation of Bourdieu is intended as neither a plenary thumbs-up nor an acquiescence to his particular conclusions about food and dining. Rather, it is to test whether, necessary changes being made, aspects of his study can apply to offal eating in modern Anglophone society. The following provides a useful starting point: "Consumption is... a stage in a process of communication, that is, an act of deciphering, decoding, which presupposes practical or explicit mastery of a cipher or code." ${ }^{17}$ Although Bourdieu refers here to engagement with artworks, let us substitute offal and take "consumption" literally. Might the body of knowledge and opinion put forth in a selection of cookery books and food-centered television programs constitute a code or language? Might access to and familiarity with this language allow an engagement with particular culinary customs that signal the identity of their users? Bourdieu appears reluctant to admit that choices about food have the same significance he cedes to other domains, preeminently music. Cooking, he asserts, belongs to "illegitimate extracurricular culture" and as such is "only valorized to the strict extent of its technical efficiency, without any social added-value." 18 A key consideration here is the extent to which cooking and eating are understood as separate in terms of their potential to signify distinction. Bourdieu's separation has been rendered untenable by the evolution of a food culture in which informed purchasing, preparation, home entertaining, dining out, and the inculcation of culinary wisdom from the food media form a continuum of associated activities. Social difference is articulated by a vocabulary and, through food, acquired from those interacting elements. Social transit, particularly aspiration, may be charted by the extent to which such elements augment, interpellate, or entirely displace the foods and food values of upbringing.

In her essay "Crafting Grand Cru Chocolates in Contemporary France," Susan Terrio specifically criticizes Bourdieu's treatment of consumption, culture, and taste as "largely arbitrary and static." ${ }^{19}$ Terrio observes that he neglects how objects may not only operate as fixed-value markers but also "play a role in blurring or subverting status continuities." Bourdieu is also charged with a failure to recognize "the impact of cultural taste makers." 20 Terrio points to a changed culinary landscape in which certain types of food knowledge have become concentrated in the middle class:

In France as well as other postindustrial economies, rising levels of per capita income and greater disposable income have produced a broader middle class of consumers with the financial means to adopt a "reflexive" attitude toward the consumption of goods in general and food in particular.... Their search for differentiation and authenticity in the consumption of food is reflected in the growing international demand for gourmet cuisine. ${ }^{21}$

Harvey Levenstein describes changing American tastes of the 1970 in similar terms. Although during the twentieth century the United States developed a largely homogenous national diet shared by people of different means and ethnicities - indeed conformity to such a diet was understood as a badge of Americanness - in the 1970s "the social classes again diverged in their food tastes and expectations." 22

For Levenstein this "revival of cooking and eating as status symbols" was especially noteworthy in that "high status could now be derived from preparing the right foods - not just consuming them." ${ }^{23}$ In light of such arguments, Bourdieu's finding that "it is among manual workers that most time and interest is devoted to cooking" 24 appears rooted in time and place. Terrio's criticism, that he fails to acknowledge the mobility of objects and the role of opinion formers, is borne out by a consideration of the foodstuffs and preferences he associates with the working class. Bourdieu points to such items as charcuterie, pork, pot-au-feu, and andouillette, 


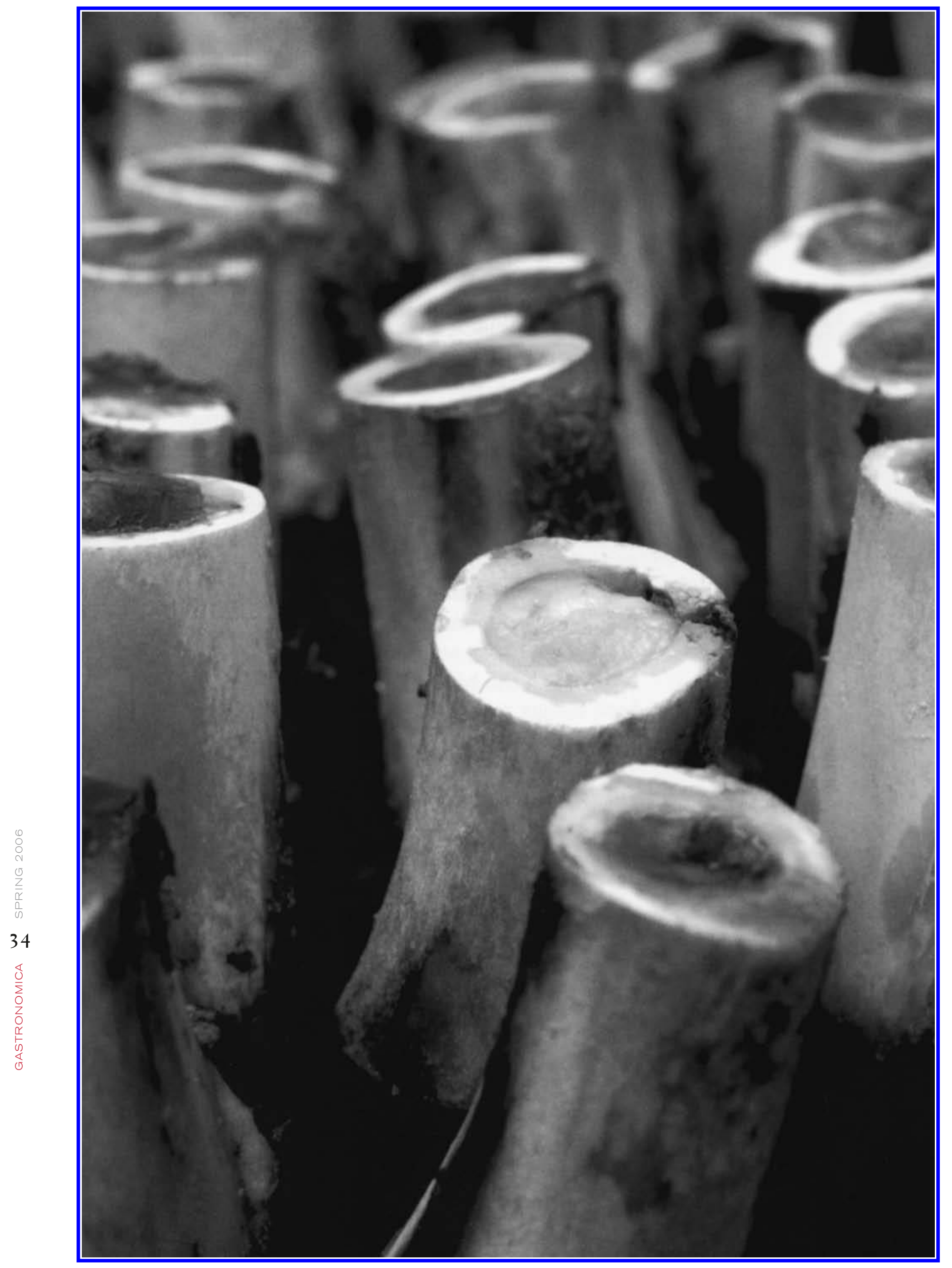


foodstuffs that in his scheme signify the values "salty-fattyheavy-strong-simmered-cheap-nourishing," ${ }^{25}$ as representing what manual workers prefer to eat. Yet this is precisely the cuisine that has enjoyed a recent surge in popularity among mondaine British and American diners. Anthony Bourdain asserts that Fergus Henderson's restaurant, St. John in London's Smithfield, and the associated cookbook, Nose to Tail Eating, first published in 1999, played a determining role in shaping the fare of other restaurants and swaying the tastes of diners: "Every time you see pork belly or bone marrow, kidneys or trotters (increasingly 'hot' offerings) on an American menu you might well owe a debt of thanks to Fergus....Anytime you see cheeks, tripes or marrow on a New York City menu, you can feel the ripples of his influence." 26

In a similar vein, Bourdain describes the restaurant Brasserie Les Halles in New York as founded on an "enthusiasm for slabs of French-cut meat, raw beef, high-fat charcuterie and organ meat." ${ }^{27}$ Such restaurants, and their associated cookbooks, clearly do not service and address the constituency of consumers to whom Bourdieu linked these foods. Rather, the foods have been relocated in the register of social distinction as a consequence of their appropriation and re-presentation by influential tastemakers. It is not claimed that those evincing enthusiasm for this offal-heavy cuisine map onto the expanded middle class of increasingly discriminating consumers described by Terrio, though they may be understood as a subset of it. Not unlike offal itself, the new offal eaters can be interpreted as an outcome at the margins, a by-product of a distinction-seeking culture in which fashions are prompted and impelled by trendsetters who revisit, modify, and commodify the tastes and practices of other times and places. Notwithstanding the more specific criticisms of Bourdieu - that he does not recognize, or anticipate, the fluidity of the very terms of difference he so exhaustively considers - his sense of a social landscape in which seemingly innocent preferences amount to a concatenation of profound and socially constitutive signs is essentially apt for understanding offal today. To be familiar with not only such traditionally cachet-laden foods as foie gras but also calves' liver, tripe, brawn, and kidneys is to bespeak participation and membership in an elite social stratum.

\section{Television and the Tastemakers}

A comprehensive survey of television cookery, let alone such other media manifestations as restaurant reviews, Sunday supplement food pages, gourmet and catering magazines, and radio food programs, is an undertaking for another, more substantial study. Addressed below are those aspects that appear most germane to the revival and transfiguration of offal. From the 199os British television has incorporated an increased number of cooks, chefs, and gourmets whose culinary idioms have been sympathetic to offal, meat, and game. Although they do not necessarily share a gastronomic ideology, it is notable that a number of these-largely malecookery TV hosts have used related themes and espoused approaches to food in which similar terms and ideas recur. An enthusiasm for the vernacular, both for the sourcing of local products and the revival of regional and national dishes - including offal dishes - has been evident. In her essay "Cooking the Books: Global or Local Identities in Contemporary British Food Cultures?" Alison James observes the "movement towards a more localized, even parochial, taste in food" 28 as the "nostalgic" part of a complex of culinary trends in which the other elements, "global food," "expatriate food," and "food creolization," exert radically different influences. James notes, though, that interpretations of food in terms of authenticity and a sense of food's capacity to shore up, alter, and create identities for its consumers connect all four categories. Questions of authenticity underpin the discourse of truth relative to meat and offal in which diners engage with a body of knowledge that concerns the origins of their food and the process of its journey to the plate. Such understanding is linked to a prevailing climate in which consumers with the financial means and disposition query the provenance of their purchases generally, motivated by considerations including food miles, organic farming, welfare standards, fair trade, and the preferred status such purchasing confers.

An ostensible openness regarding the topic of cruelty to animals has featured in several series and the volumes associated with their hosts. As part of the tendency to address issues other than what may be done with raw ingredients, programs have come to feature the production, management, and harvesting of food resources, including those reared or otherwise acquired through country sports. Fearnley-Whittingstall's River Cottage series and Rick Stein's Food Heroes have included episodes in which animals have been shot in the wild before being prepared for the table. Common to both has been the argument that such practices are preferable to those of factory farming and thus represent an honest, morally coherent approach to meat eating. This approach is related to that of the offal eater in that it acknowledges the bloody facts - perhaps seeking partially to ameliorate them through informed purchasing - and in so doing amounts to a species of superiority over those who balk at offal, game, and the truth about their own food. 
For Fearnley-Whittingstall a recurring motif is the figure of the downsizer, the urban professional who has quit city life for a rural existence that involves farming and the aspiration to self-sufficiency in horticulture and animal rearing, or at least participation in a local exchange economy of goods and labor. Positioning himself in this role-a structuring fiction that elides his simultaneous employment as TV personality, author, and celebrity-Fearnley-Whittingstall represents the consumption of offal as material to the smallscale farmer's creed: "Waste is not acceptable. It's all or nothing." ${ }^{29}$ Rick Stein shares Fearnley-Whittingstall's emphasis on the moral preferability of small-scale concerns and rejection of mass-produced foodstuffs as inauthentic but concentrates on artisanal food producers and rural businesses, valorizing them as the keeper-saviors of traditional practices and products. Whereas Stein and Fearnley-Whittingstall have at times strained to dislocate shooting and fishing from their traditional associations of aristocratic privilege and landownership, Jennifer Paterson and Clarissa Dickson-Wright, in Two Fat Ladies and Clarissa and the Countryman, reveled in such connotations and the presentation of such a milieu. Eschewing the studio-set, stove-bound role occupied by the overwhelming majority of female television cooks, they adopted the peripatetic mode increasingly embraced by their male counterparts, hunting and gathering the foodstuffs they later prepared.

Levenstein observes the trend in America since the mid-1970s toward a "new machismo in the kitchen," wherein cooking and the food media have become an increasingly masculine domain, the status of culinary journalism has been elevated, and features on "prominent celebrities such as actors Danny Kaye and Walter Matthau and Hollywood director John Frankenheimer as outstanding home cooks" have appeared..$^{30}$ Anthony Bourdain represents the contemporary culmination of this trend. His autobiographical writing and cookery work flaunt a predilection for blood and guts, risk taking, and food to unnerve the squeamish. Sharing a "naked contempt for vegetarians" 31 with Paterson and DicksonWright, admiring Henderson's food as "an outrageously timed head butt to the growing hordes of politically correct, the PETA people, [and] the European Union," ${ }^{2}$ Bourdain describes himself thus:

I have always liked to think of myself as the Chuck Wepner of cooking. Chuck was a journeyman "contender", referred to as the "Bayonne Bleeder" back in the Ali-Frazier era. He could always be counted on to last a few solid rounds without going down, giving as good as he got. I admired his resilience, his steadiness, his ability to get it together, to take a beating like a man. ${ }^{33}$
Both Bourdain and Fearnley-Whittingstall exhort their readers toward cooking and eating in terms of "adventure," extolling the virtues of potentially off-putting foodstuffs, especially offal. ${ }^{34}$ In his recipe for tripes "les halles," Bourdain frames the preparation and serving of the dish in terms of the ambitious, distinction-seeking home cook, fully aware of tripe's reputation and presenting it with virile bravado:

C'mon bold adventurer! Depending on who you hang with, this dish will either make or lose you a lot of friends. One thing's for sure:

They'll never forget you....I suggest throwing a big, rowdy party, getting your guests liquored up, and, when they finally start complaining, "Where's the guacamole and the remaki?" hauling out a big, beautiful tub of steaming hot guts. ${ }^{35}$

Offal is thereby figured as a singularly potent option in the repertoire of the host seeking to impress, a formidable instrument in the arms race of reciprocal hospitality. In a middle-class dinner party environment, where repute may be sought through the use of ingredients distinguished by their echt or recherché properties and through the casual display of tableware and culinary gadgetry-especially professionalgrade appliances - the serving of offal connotes dash and gutsy adroitness. Offal also acquires value through its potential for provoking food talk, about its origins (anatomical and otherwise), the difficulty or ease of its preparation, and recollections of similar dishes eaten elsewhere. To know what sweetbreads are, or chimo, ${ }^{36}$ or why a woodcock need not be eviscerated before roasting ${ }^{37}$ is to participate in the flaunting and exchange of esoteric food lore.

Though programs and publications aimed at middleclass sophisticates reveal an increasing regard for offal, it may be observed that this trend has not percolated to those programs more clearly targeting a wider audience. Ready Steady Cook and Can't Cook, Won't Cook very rarely feature offal, even in its more "acceptable" manifestations. Such daytime offerings adhere closely to a rubric of studio-based television entertainment in which participants descend from the audience and are prompted to recite embarrassing or amusing anecdotes about their own lives before assisting the professional cook-host in against-the-clock competition. Comic hay is made from the juxtaposition of competence and incompetence, as epitomized by The Generation Game, in which the professionals demonstrate mastery through quicksilver knife skills or the creation of spun-sugar baskets while the contestants commonly struggle in the execution of these and simpler tasks. Although the programs abound with references and exhortations to what may be tried "at home" and viewers are advised that recipes may be found 
on Ceefax, ${ }^{38}$ the programs lack the sense of a mass of viewers faithfully replicating the dishes they have seen. Although food is the ostensible topic, banter and humor are paramount. The communion of viewer-cooks seems a product only of those series accompanied by glossy books that triangulate program and audience, preeminently those of Delia Smith, whose famously specific stipulations with regard to ingredients, utensils, and other books have produced sudden shortages of the items she names and secured her inclusion in the dictionary as a byword for methodical observance. The existence of the accompanying book is a clear indicator of the social and economic status of the imagined viewership: to "do a Delia" likely signifies a shelf of cookbooks and the means and inclination to buy them.

\section{Poor Food}

For Hattie Ellis industrialization is the overarching reason for the decline in British cookery. A disconnection between people and the land is caused by migration to the growing cities in search of work:

At this point, we lost much of the "peasant" base that usually underpins a strong food culture, rooted as it is in people who understand the products of the land....In 1811, 35 per cent of Englishmen worked in agriculture; a century later it was just 12 per cent. (In France, 53 per cent still worked in farming in 1856 and 43 per cent in 1901.) $)^{39}$

In America, Levenstein cedes a central role to the food processing giants in this distancing of consumers from the origins of their food and the concomitant loss of foodpreparation skills that were once widely shared. He points to the relation between food companies and the teachers of home economics as one that is particularly insidious. Of an assurance by the home economist Ruth Atwater in 1932 regarding the equivalence of "food value" between commercially canned and home-prepared foods published in the Journal of Home Economics - a journal edited by her sister Helen-he observes:

$[\mathrm{N}] \mathrm{o}$ one seems to have thought twice about the food processors having become an indispensable source of funding for the American Home Economics Association, publisher of the journal. Since they also provided an increasing number of jobs for home economists - who developed recipes and instructional materials using their products for home economists in the schools - there was never a shortage of professional "dieticians" (a rubric used increasingly by home economists who specialized in food) to provide similar testimonials to canning and other forms of processing. ${ }^{40}$
The industry journal Food Processing openly discussed the extent to which a lack of cooking skills helped constitute a market for their products. Noting in 1966 that 40 percent of new brides were teenagers "with relatively meager home making skills [who] comprise a huge market for frozen and canned goods," ${ }^{41}$ the journal inadvertently testified to the efficacy of the relation between the food giants and the home economists in teaching young women and their mothers before them how to not cook. In her 1979 revision of English Food, Jane Grigson berates the teachers of domestic science as the perpetrators of "crimes against good food," criticizing the teaching specifically in terms of its reliance on ready-prepared ingredients. What value, she asks, is there in teaching only "The skill to turn on the tap and mix the mix to a dough? The skill to operate a tin-opener? The skill to read the instructions on the packet or tin? The skill to spoon the filling into a dish?"42 For Grigson, to sidestep a primary engagement with food, for the teaching of cookery not to be the encounter with and transformation of raw ingredients, is to render the exercise pointless.

If home economics tends to be characterized as broadly unhelpful, the consistency with which cookery writers emphasize the positive importance of family influence is even more striking. Helou explains how, as a child in Lebanon, she learned to eat chicken offal: "My mother had taught us how to crack open the chicken's skull to remove the tiny brains without damaging them; and she had also shown us how to peel the lizard-like skin off the feet to enjoy the gelatinous meat." ${ }^{3}$ Joanne Harris, in The French Kitchen, also lauds the maternal line by means of which a culinary legacy is imparted.

"Cooking is a social activity. My mother's kitchen - and my grandmother's, and my great-grandmother's - was open to all comers." ${ }^{44}$ However, accounts of a childhood spent in Britain or America tend to be less positive about the food. Bourdain describes his early culinary epiphanies, paramount among them his first oyster, coming only as a result of a trip to France, ${ }^{45}$ while Nigel Slater's recollections of the food of his youth in the Midlands lean heavily toward ready-prepared dishes, many of them-Angel Delight (an instant dessert mix), Arctic Roll (ice cream encased in sponge cake), Vesta Curry (a packaged Indian-style meal) - disappointing simulacra of more authentic fare. ${ }^{46}$ Fiona Hamilton-Fairley, who runs the Kids Cookery School project in west London, describes a modern British food climate in which children and adults alike share an ignorance of the origins of their food and may never have known communal family meals: "We have a big problem....We have lost the thread of family food." ${ }^{4}$

Between them, food writers and anthropologists chart a distancing process, reaching back at least to the early twentieth century, whereby a majority of people were successfully 
encouraged to approach their cooking and eating in terms of convenience. As reliance on prepared goods became ingrained, familiarity with staple ingredients diminished. Food manufacturers profited and continue to profit from this situation, recognizing that revenues accrued by volume are necessarily limited by population size and perceiving "value-added" as the avenue of increased yield. Accordingly, consumers have come to purchase less of such staples as flour, sugar, oil, and cheap cuts, buying instead more goods in which those ingredients have already been combined and prepared on an industrial scale. The production line has significantly displaced the kitchen. Another effect of this process has been the diminishment in influence of the most primary of food producers - farmersespecially those operating on a small scale. Lacking the direct access to consumers enjoyed by the multinationals, farmers increasingly produce foodstuffs on terms dictated by the giant supermarket chains or publicly traded conglomerates, their near-anonymous output alchemized into shopper-friendly forms by famous brand names or supermarket-owned labels.

Increasingly, cookery writers and Tv hosts have advocated a reconnection between farmers and consumers. This has been a cornerstone of the trend - for those able to afford ittoward determining the provenance of goods, choosing, when possible, local produce and small suppliers. Readers and viewers are urged to "find a really good organic butcher or cheesemonger or baker. Visit markets instead of supermarkets. Rediscover the joy of eating locally grown produce." ${ }^{48}$ Eating England concludes with a seventy-page guide to "chefs, food producers and sellers around England" 49 that presupposes a readership interested equally in dining out and buying foodstuffs to prepare at home. Fearnley-Whittingstall acknowledges a major drawback of practicing a provenance-conscious approach to food buying but asserts the relationship between price and quality: "I think it would make sense for almost all of us to pay more money for less meat, of better quality. I'd go further and say we should be ready to pay twice as much money for half as much meat-from animals that have lived infinitely better lives." ${ }^{50}$ Although he hurries to indicate that such expense can be mitigated by purchasing less costly cuts and practicing "meat thriff" - a topic to which he devotes a chapter-his and similar exhortations present significant difficulties for a majority of consumers. Or, rather, they would present difficulties if that majority actually read and watched the texts and programs in which these appeals are made. A fundamental problem is that the small specialist retailers whom consumers are encouraged to patronize are not uniformly accessible. In Britain affluent urban enclaves and prosperous market towns are likely to be well served by organic butchers, fishmongers, and the like, as they are also likely to be well served by restaurants - completing a circle of potential culinary experience. Conversely, many failed housing projects are characterized by the closure of many of their retail stores-indicative of the failure of the postwar project to create ready-made communities-leaving behind multipurpose outlets that function also as newsagents and liquor stores, selling foods only with a long shelf life or high turnover alongside tobacco products, alcohol, and candy. Often located next to take-out food businesses, and commonly offering little in the way of fresh produce, such shops are obliged to stay open long hours to compete with the nearest supermarket, which is likely to offer a free bus service to and from the development. Unless the organic grocer is within walking distance of one's home, car ownership is likely to be an important factor in determining where one shops.

When Fearnley-Whittingstall describes liver "achingly fresh from the abattoir," ${ }^{11}$ he unearths a key explanation for the disappearance of offal from the majority diet and its reanimation in the foodways of a culinary elite. The susceptibility of organ meat to rapid deterioration had once served as the guarantee for the rural poor-either as producers or purchasers - that certain parts would be available to them, living as they did in close proximity to the places of slaughter. Migration to the cities and, more recently, increasing regulation of the abattoir business, resulting in the closure of most small concerns, has produced a distance - both literal and figurative-between a food and its former consumers. Although advances in transportation and refrigeration technologies erase the literal distance, the loss of the old imperative to make rapid use of the most vulnerable materials has ensured another, equally profound, separation. Where the killing of a pig had once been the occasion for family or community to work together to make certain that no part was wasted -through the preparation of sausages and black puddings, the salting and curing of roasts, and the early consumption of soft tissues - its vanishing from common experience has left all but a tiny minority unfamiliar with propinquity to livestock, its slaughter, and its offal. For others familiarity with foods and their origins has become a mark of prestige. Although this is highly unlikely to resemble the experience of the thrifty cottager, it includes a certain vaunting of the understanding that to eat meat is to participate in an economy of life and death. For the modern offal eaters their knowledge and consumption of liver, kidneys, and trotters signifies an especially pronounced participation in this culture of food awareness, an engagement with food at its most primary. With majority tastes shepherded toward convenience and away from blood and guts, offal has acquired a new potential to signify discrimination. $\odot$ 
NOTES

1. Carole Counihan and Penny Van Esterik, eds., Food and Culture: A Reader (New York: Routledge, 1997), 3.

2. Anissa Helou, The Fifth Quarter: An Offal Cookbook (Bath: Absolute Press, 2004), 107

3. Anthony Bourdain, with Jose De Meirelles and Philippe Lajaunie, Anthony Bourdain's Les Halles Cookbook: Strategies, Recipes, and Techniques of Classic Bistro Cooking (New York: Bloomsbury, 2004), 13.

4. Hugh Fearnley-Whittingstall, The River Cottage Meat Book (London: Hodder \& Stoughton, 2004), 181.

5. Margaret Visser, “The Sins of the Flesh," Granta 52 (1995): 126.

6. Helou, Fifth Quarter, 13 .

7. Fergus Henderson, Nose to Tail Eating: A Kind of British Cooking (London: Bloomsbury, 2004), no pagination.

8. Helou, Fifth Quarter, 8.

9. Hattie Ellis, Eating England: Why We Eat What We Eat (London: Mitchell Beazley, 2001), 103

10. Fearnley-Whittingstall, River Cottage, 182

11. Ibid., 426 .

12. Ibid.

13. Henderson, Nose to Tail Eating, back cover, emphasis added.

14. Ibid., 100 .

15. An earlier Oliver vehicle had involved the training of unemployed young people to work in a restaurant.

16. Pierre Bourdieu, Distinction: A Social Critique of the Judgement of Taste, Richard Nice, trans. (London: Routledge, 1989).

17. Ibid., 2.

18. Ibid., 25 .

19. Susan Terrio, "Crafting Grand Cru Chocolates in Contemporary France," in The Cultural Politics of Food and Eating, James Watson and Melissa Caldwell, eds. (Malden, MA: Blackwell, 2005), 150.

20. Ibid.

21. Ibid.

22. Harvey Levenstein, Paradox of Plenty: A Social History of Eating in Modern America (Berkeley and Los Angeles: University of California Press, 2003), 222.

23. Ibid.

24. Bourdieu, Distinction, 187 .

25. Ibid., 186-187.
26. Bourdain, introduction to Henderson, Nose to Tail Eating, no pagination.

27. Bourdain, Les Halles, 21.

28. Alison James, "Cooking the Books: Global or Local Identities in Contemporary British Food Cultures?” in Cross-Cultural Consumption: Global Markets, Local Realities, D. Howes, ed. (London: Routledge, 1996), 81.

29. Fearnley-Whittingstall, River Cottage, 182.

30. Levenstein, Paradox of Plenty, 226.

31. Anthony Bourdain, Kitchen Confidential: Adventures in the Culinary Underbelly (New York: Harper Collins, 2001), 5 .

32. Bourdain, introduction to Henderson, Nose to Tail Eating, no pagination.

33. Bourdain, Kitchen Confidential, 4 .

34. Fearnley-Whittingstall, River Cottage, 9; Bourdain, Kitchen Confidential, 5.

35. Bourdain, Les Halles, 223.

36. An Italian term for the upper section of veal or lamb intestine containing partly digested grass.

37. Because they defecate before flying. This rule therefore assumes a woodcock shot in flight.

38. An information service accessed via television.

39. Ellis, Eating England, 37.

40. Levenstein, Paradox of Plenty, 15-16.

41. Ibid., 196.

42. Jane Grigson, extract from English Food, in M. Kurlansky, Choice Cuts: A Miscellany of Food Writing (London: Vintage, 2004), 399

43. Helou, Fifth Quarter, 8.

44. Joanne Harris and Fran Warde, The French Kitchen: A Cookbook (London: Doubleday, 2002), 8

45. Bourdain, Kitchen Confidential.

46. Nigel Slater, Toast: The Story of a Boy's Hunger (London: Harper-Perennial, 2003), 13-14.

47. Quoted in Ellis, Eating England, 211.

48. Harris, French Kitchen, 11.

49. Ellis, Eating England, 222-295.

50. Fearnley-Whittingstall, River Cottage, 29

51. Ibid., 182 . 